\title{
Flavonoids: an overview
}

\author{
A. N. Panche ${ }^{1,2}$, A. D. Diwan ${ }^{2}$ and S. R. Chandra ${ }^{1}$ \\ ${ }^{1}$ Department of Bio-Engineering, Birla Institute of Technology, Mesra, Ranchi, Jharkhand 835215, India \\ ${ }^{2}$ MGM's Institute of Biosciences and Technology, Mahatma Gandhi Mission, N-6, CIDCO, Aurangabad-431003, India
}

(Received 18 July 2016 - Final revision received 4 October 2016 - Accepted 5 October 2016)

Journal of Nutritional Science (2016), vol. 5, e47, page 1 of 15

doi:10.1017/jns.2016.41

Abstract

Flavonoids, a group of natural substances with variable phenolic structures, are found in fruits, vegetables, grains, bark, roots, stems, flowers, tea and wine. These natural products are well known for their beneficial effects on health and efforts are being made to isolate the ingredients so called flavonoids. Flavonoids are now considered as an indispensable component in a variety of nutraceutical, pharmaceutical, medicinal and cosmetic applications. This is attributed to their anti-oxidative, anti-inflammatory, anti-mutagenic and anti-carcinogenic properties coupled with their capacity to modulate key cellular enzyme function. Research on flavonoids received an added impulse with the discovery of the low cardiovascular mortality rate and also prevention of CHD. Information on the working mechanisms of flavonoids is still not understood properly. However, it has widely been known for centuries that derivatives of plant origin possess a broad spectrum of biological activity. Current trends of research and development activities on flavonoids relate to isolation, identification, characterisation and functions of flavonoids and finally their applications on health benefits. Molecular docking and knowledge of bioinformatics are also being used to predict potential applications and manufacturing by industry. In the present review, attempts have been made to discuss the current trends of research and development on flavonoids, working mechanisms of flavonoids, flavonoid functions and applications, prediction of flavonoids as potential drugs in preventing chronic diseases and future research directions.

Key words: Flavonoids: Structure and composition: Biological activity: Research trends: Future research directions

Flavonoids are an important class of natural products; particularly, they belong to a class of plant secondary metabolites having a polyphenolic structure, widely found in fruits, vegetables and certain beverages. They have miscellaneous favourable biochemical and antioxidant effects associated with various diseases such as cancer, Alzheimer's disease (AD), atherosclerosis, etc. ${ }^{(1-3)}$. Flavonoids are associated with a broad spectrum of health-promoting effects and are an indispensable component in a variety of nutraceutical, pharmaceutical, medicinal and cosmetic applications. This is because of their antioxidative, anti-inflammatory, anti-mutagenic and anti-carcinogenic properties coupled with their capacity to modulate key cellular enzyme functions. They are also known to be potent inhibitors for several enzymes, such as xanthine oxidase (XO), cyclo-oxygenase (COX), lipoxygenase and phosphoinositide 3-kinase ${ }^{(4-6)}$.

In nature, flavonoid compounds are products extracted from plants and they are found in several parts of the plant. Flavonoids are used by vegetables for their growth and defence against plaques ${ }^{(7)}$. They belong to a class of low-molecular-weight phenolic compounds that are widely distributed in the plant kingdom. They constitute one of the most characteristic classes of compounds in higher plants. Many flavonoids are easily recognised as flower pigments in most angiosperm families. However, their occurrence is not restricted to flowers but are found in all parts of plants ${ }^{(8)}$. Flavonoids are also abundantly found in foods and beverages of plant origin, such as fruits, vegetables, tea, cocoa and wine;

Abbreviations: A $\beta$, amyloid protein; AChE, acetylcholinesterase; AD, Alzheimer's disease; BACE-1, $\beta$ active site cleavage enzyme-1; BChE, butyrylcholinsterase; COX, cyclooxygenase; NDM-1, New Delhi metallo- $\beta$-lactamase-1; XO, xanthine oxidase.

* Corresponding author: Dr A. D. Diwan, email arvinddiwan@yahoo.com 
hence they are termed as dietary flavonoids. Flavonoids have several subgroups, which include chalcones, flavones, flavonols and isoflavones. These subgroups have unique major sources. For example, onions and tea are major dietary sources of flavonols and flavones.

Flavonoids play a variety of biological activities in plants, animals and bacteria. In plants, flavonoids have long been known to be synthesised in particular sites and are responsible for the colour and aroma of flowers, and in fruits to attract pollinators and consequently fruit dispersion to help in seed and spore germination, and the growth and development of seedlings ${ }^{(9)}$. Flavonoids protect plants from different biotic and abiotic stresses and act as unique UV filters ${ }^{(10)}$, function as signal molecules, allopathic compounds, phytoalexins, detoxifying agents and antimicrobial defensive compounds. Flavonoids have roles against frost hardiness, drought resistance and may play a functional role in plant heat acclimatisation and freezing tolerance ${ }^{(11)}$. Jorgensen ${ }^{(12)}$ has mentioned that the early advances in floral genetics were primarily due to mutation techniques making an impact on flavonoidderived flower colours, and demonstrated that functional gene silencing in plants was associated with flavonoid biosynthesis. Flavonoids have been ascribed positive effects on human and animal health and the current interest is for disease therapy and chemoprevention. Currently there are about 6000 flavonoids that contribute to the colourful pigments of fruits, herbs, vegetables and medicinal plants. Dixon \& Pasinetti ${ }^{(13)}$ reviewed plant flavonoids and isoflavonoids in detail and discussed their applications to agriculture and neurosciences in human beings. Kumar \& Pandey ${ }^{(14)}$ reviewed the protective roles of flavonoids against human diseases as well as their functions in plants. Recently Panche et al. ${ }^{(15)}$, while reviewing $\mathrm{AD}$ and current therapeutic methods, discussed in detail uses of flavonoids as plant secondary metabolites for the treatment of $\mathrm{AD}$ and the mechanisms involved. In the present review, attempts have been made to discuss the current trends of research and development on flavonoids, their applications as dietary and health benefits along with broad classification and future research directions.

\section{Classification}

Flavonoids can be subdivided into different subgroups depending on the carbon of the $\mathrm{C}$ ring on which the $\mathrm{B}$ ring is attached and the degree of unsaturation and oxidation of the $\mathrm{C}$ ring (Fig. 1). Flavonoids in which the $\mathrm{B}$ ring is linked in position 3 of the $\mathrm{C}$ ring are called isoflavones. Those in which the $\mathrm{B}$ ring is linked in position 4 are called neoflavonoids, while those in which the B ring is linked in position 2 can be further subdivided into several subgroups on the basis of the structural features of the $\mathrm{C}$ ring. These subgroups are: flavones, flavonols, flavanones, flavanonols, flavanols or catechins, anthocyanins and chalcones (Fig. 1).

\section{Flavones}

Flavones are one of the important subgroups of flavonoids. Flavones are widely present in leaves, flowers and fruits as glucosides. Celery, parsley, red peppers, chamomile, mint and ginkgo biloba are among the major sources of flavones. Luteolin, apigenin and tangeritin belong to this subclass of flavonoids (Fig. 2). The peels of citrus fruits are rich in the polymethoxylated flavones, tageretin, nobiletin and sinensetin ${ }^{(16)}$. They have a double bond between positions 2 and 3 and a ketone in position 4 of the $\mathrm{C}$ ring. Most flavones of vegetables and fruits have a hydroxyl group in position 5 of the A ring, while hydroxylation in other positions, for the most part in position 7 of the $\mathrm{A}$ ring or $3^{\prime}$ and $4^{\prime}$ of the $\mathrm{B}$ ring, may vary according to the taxonomic classification of the particular vegetable or fruit.

\section{Flavonols}

Flavonols are flavonoids with a ketone group. They are building blocks of proanthocyanins. Flavonols occur abundantly in a variety of fruits and vegetables. The most studied flavonols are kaempferol, quercetin, myricetin and fisetin (Fig. 2). Onions, kale, lettuce, tomatoes, apples, grapes and berries are rich sources of flavonols. Apart from fruits and vegetables, tea and red wine are also sources of flavonols. Intake of flavonols is found to be associated with a wide range of health benefits which includes antioxidant potential and reduced risk of vascular disease.

Compared with flavones, flavonols have a hydroxyl group in position 3 of the $\mathrm{C}$ ring, which may also be glycosylated. Like flavones, flavonols are very diverse in methylation and hydroxylation patterns as well and, considering the different glycosylation patterns, they are perhaps the most common and largest subgroup of flavonoids in fruits and vegetables. For example, quercetin is present in many plant foods ${ }^{(17)}$.

\section{Flavanones}

Flavanones are another important class which is generally present in all citrus fruits such as oranges, lemons and grapes. Hesperitin, naringenin and eriodictyol are examples of this class of flavonoids (Fig. 2). Flavonones are associated with a number of health benefits because of their free radicalscavenging properties. These compounds are responsible for the bitter taste of the juice and peel of citrus fruits. Citrus flavonoids exert interesting pharmacological effects as antioxidant, anti-inflammatory, blood lipid-lowering and cholesterollowering agents. Flavanones, also called dihydroflavones, have the $\mathrm{C}$ ring saturated; therefore, unlike flavones, the double bond between positions 2 and 3 is saturated and this is the only structural difference between the two subgroups of flavonoids. Over the past 15 years, the number of flavanones has significantly increased ${ }^{(17)}$.

\section{Isoflavonoids}

Isoflavonoids are a large and very distinctive subgroup of flavonoids. Isoflavonoids enjoy only a limited distribution in the plant kingdom and are predominantly found in soyabeans and other leguminous plants. Some isoflavonoids have also been reported to be present in microbes ${ }^{(18)}$. They are also found 


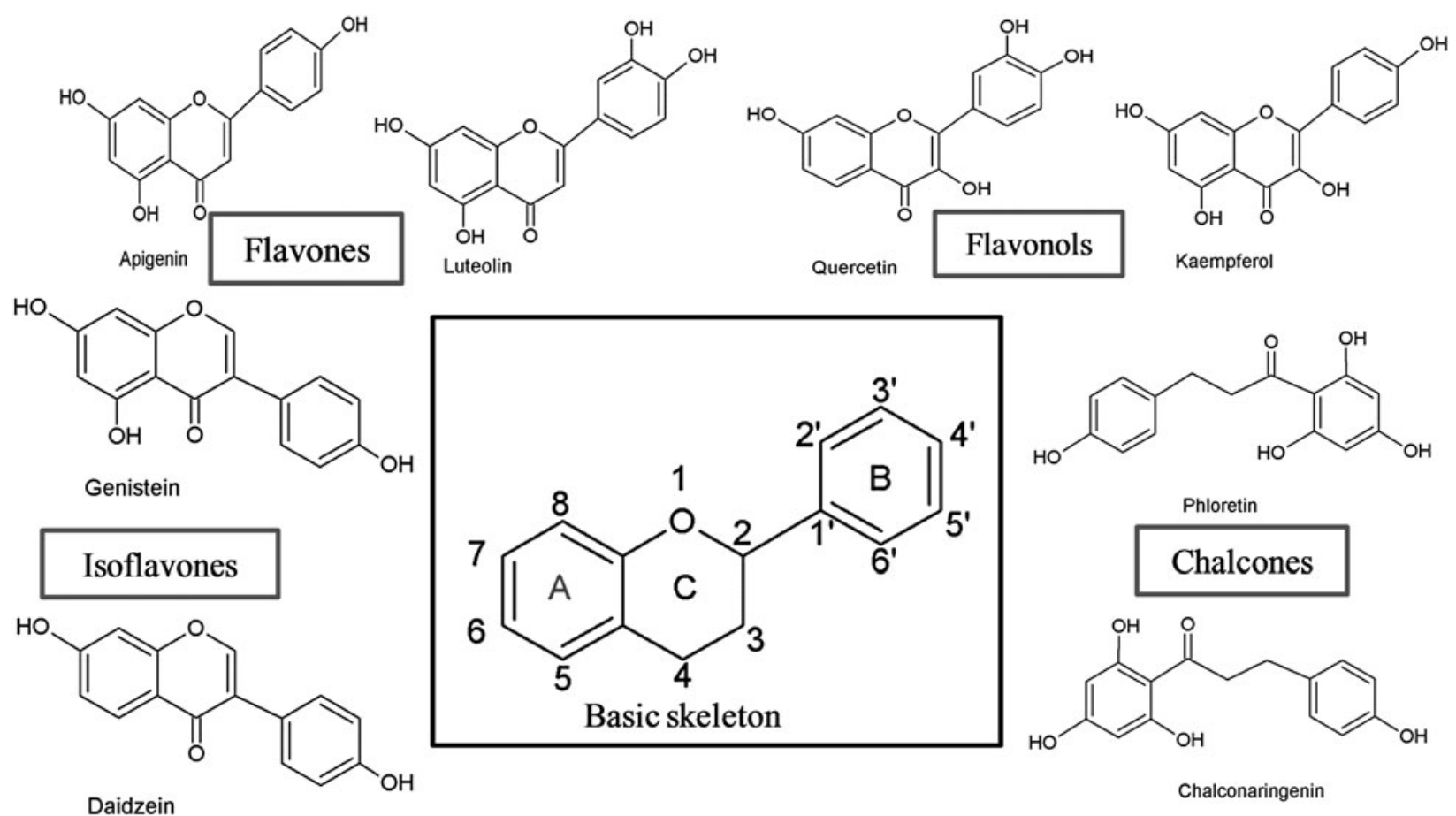<smiles>O=C1CC(c2ccc(O)cc2)Oc2cc(O)cc(O)c21</smiles><smiles></smiles>

Fig. 1. Basic skeleton structure of flavonoids and their classes.

to play an important role as precursors for the development of phytoalexins during plant microbe interactions ${ }^{(19,20)}$. Isoflavonoids exhibit tremendous potential to fight a number of diseases. Isoflavones such as genistein and daidzein are commonly regarded to be phyto-oestrogens because of their oestrogenic activity in certain animal models (Fig. 2). Szkudelska \& Nogowski reviewed the effect of genistein inducing hormonal and metabolic changes, by virtue of which they can influence various disease pathways ${ }^{(21)}$.

\section{Neoflavonoids}

Neoflavonoids are a class of polyphenolic compounds. While flavonoids have a 2-phenylchromen-4-one backbone, neoflavonoids have a 4-phenylchromen backbone with no hydroxyl group substitution at position 2 . The first neoflavone isolated from natural sources in 1951 was calophyllolide from Calophyllum inophyllum seeds. It is also found in the bark and timber of the Sri Lankan endemic plant Mesua thwaitesii ${ }^{(22-24)}$.

\section{Flavanols, flavan-3-ols or catechins}

Flavanonols, also called dihydroflavonols or catechins, are the 3-hydroxy derivatives of flavanones. They are a highly diversified and multisubstituted subgroup. Flavanols are also referred to flavan-3-ols as the hydroxyl group is always bound to position 3 of the $\mathrm{C}$ ring. Unlike many flavonoids, there is no double bond between positions 2 and 3. Flavanols are found abundantly in bananas, apples, blueberries, peaches and pears (Fig. 2).

\section{Anthocyanins}

Anthocyanins are pigments responsible for colours in plants, flowers and fruits. Cyanidin, delphinidin, malvidin, pelargonidin and peonidin are the most commonly studied anthocyanins (Fig. 2). They occur predominantly in the outer cell layers of various fruits such as cranberries, black currants, red grapes, merlot grapes, raspberries, strawberries, blueberries, bilberries and blackberries. Stability coupled with health benefits of these compounds facilitate them to be used in the food industry in a variety of applications ${ }^{(25)}$. The colour of the anthocyanin depends on the $\mathrm{pH}$ and also by methylation or acylation at the hydroxyl groups on the $\mathrm{A}$ and $\mathrm{B}$ rings ${ }^{(17)}$.

\section{Chalcones}

Chalcones are a subclass of flavonoids. They are characterised by the absence of 'ring C' of the basic flavonoid skeleton structure shown in Fig. 1. Hence, they can also be referred to as open-chain flavonoids. Major examples of chalcones include 


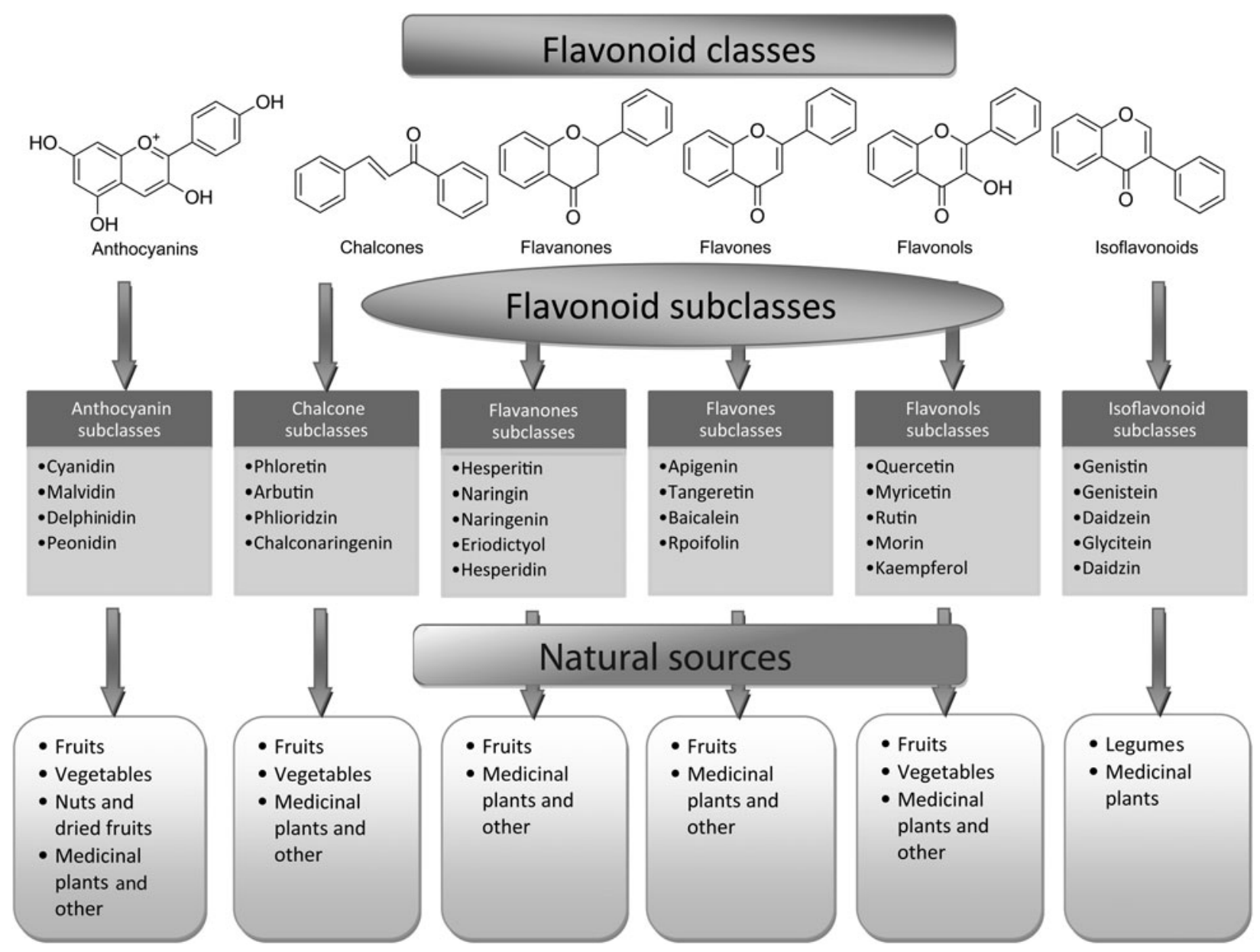

Fig. 2. Flavonoid classes, subclasses and natural sources.

phloridzin, arbutin, phloretin and chalconaringenin. Chalcones occur in significant amounts in tomatoes, pears, strawberries, bearberries and certain wheat products. Chalcones and their derivatives have garnered considerable attention because of numerous nutritional and biological benefits. Table 1 describes the food sources of all dietary flavonoids discussed throughout the article for their bioactivity and research trends ${ }^{(26-63)}$. The intake of flavonoids through food sources could be the simplest and safest way to combat diseases as well as modulate activities.

\section{Current research and trends on flavonoids}

\section{Anti-cholinesterase activity}

Acetylcholinesterase (AChE) is a key enzyme in the central nervous system and inhibition of it leads to increases of neural acetylcholine levels which is one of the therapies for symptomatic relief of mild to moderate $\mathrm{AD}^{(64)}$. Hence the inhibition of cholinesterases is one of the central focus for drug development to combat AD. A number of flavonoids have been reported for their anti-cholinesterase activity. The in vitro inhibitory studies done on various flavonoids like quercetin, rutin, kaempferol 3-O- $\beta$-D-galactoside and macluraxanthone showed that quercetin and macluraxanthone possess a concentration-dependent inhibition ability against AChE and butyrylcholinsterase $(\mathrm{BChE})^{(34)}$. Macluraxanthone was found to be the most potent and specific inhibitor of both the enzymes with $50 \%$ inhibitory concentration $\left(\mathrm{IC}_{50}\right)$ values of 8.47 and $29.8 \mu \mathrm{M}$, respectively. The enzyme kinetic studies revealed that quercetin inhibited both the enzymes in a competitive manner whereas macluraxanthone was noncompetitive against $\mathrm{AChE}$ and competitive against $\mathrm{BChE}$. To get insight of the intermolecular interactions, molecular docking studies of these two compounds were performed at active sites of both the enzymes. The docking studies showed that macluraxanthone binds much more tightly with both the enzymes than that of quercetin. Sheng et al. ${ }^{(65)}$, while designing, synthesising and performing the evaluation of flavonoid derivatives as potent AChE inhibitors, observed that most of the flavonoid derivatives have properties of inhibitory activities to AChE. The most potent inhibitor, isoflavone derivative 10d, inhibits $\mathrm{AChE}$ with an $\mathrm{IC}_{50}$ of $4 \mathrm{~nm}$, showing a high BChE:AChE inhibition ratio (4575-fold), superior to donepezil $\left(\mathrm{IC}_{50}=12 \mathrm{~nm}, 389\right.$-fold). Molecular docking studies were also performed to explore the detailed interaction with AChE.

\section{Anti-inflammatory activity}

COX is an endogenous enzyme which catalyses the conversion of arachidonic acid into prostaglandins and thromboxanes ${ }^{(66)}$. 
Table 1. Flavonoids, their classes and rich dietary sources

\begin{tabular}{|c|c|c|c|c|}
\hline $\begin{array}{l}\text { Serial } \\
\text { no. }\end{array}$ & Flavonoid & Class & Dietary sources & References \\
\hline 1 & Quercetin & Flavonols & $\begin{array}{l}\text { Vegetables, fruits and beverages, spices, soups, fruit } \\
\text { juices }\end{array}$ & $\begin{array}{l}\text { Hertog et al. }{ }^{(26)} ; \text { Justesen \& } \\
\text { Knuthsen }^{(27)} \text {; Stewart et al. }{ }^{(28)} \text {; Zheng \& } \\
\text { Wang }^{(29)}\end{array}$ \\
\hline 2 & Rutin & Flavonols & $\begin{array}{l}\text { Green tea, grape seeds, red pepper, apple, citrus } \\
\text { fruits, berries, peaches }\end{array}$ & $\begin{array}{l}\text { Atanassova \& Bagdassarian }{ }^{(30)} ; \\
\text { Gudrais }^{(31)} \text {; Chang et al. } .^{(32)} \text {; Malagutti } \\
\text { et al. }{ }^{(33)}\end{array}$ \\
\hline 3 & Macluraxanthone & Xanthones & Maclura tinctoria (Hedge apple), Dyer's mulberry & Khan et al..$^{(34)}$ \\
\hline 4 & Genistein & Isoflavone & $\begin{array}{l}\text { Fats, oils, beef, red clover, soyabeans, psoralea, } \\
\text { lupin, fava beans, kudzu, psoralea }\end{array}$ & $\begin{array}{l}\text { Thompson et al. }{ }^{(35)} ; \text { Umpress et al. }{ }^{(36)} ; \\
\text { Krenn et al. }{ }^{(37)} \text { Coward et al. }{ }^{(38)} ; \\
\text { Kaufman et al. }{ }^{(39)}\end{array}$ \\
\hline 5 & Scopoletin & Coumarin & Vinegar, dandelion coffee & Gálvez et al. ${ }^{(40)}$ \\
\hline 6 & Daidzein & Isoflavone & Soyabeans, tofu & Zhang et al. ${ }^{(41)}$ \\
\hline 7 & Taxifolin & Flavanonol & Vinegar & Cerezoa et al. ${ }^{(42)}$ \\
\hline 8 & Naringenin & Flavanone & Grapes & Felgines et al..$^{(43)}$ \\
\hline 9 & Abyssinones & Flavanone & French bean seeds & $\begin{array}{l}\text { Rathmell \& Bendall }{ }^{(44)} \text {; Cruickshank } \\
\text { et al. }{ }^{(45)}\end{array}$ \\
\hline 10 & Rutin & Flavonol & Citrus fruits, apple, berries, peaches & Cruickshank et al. ${ }^{(45)}$; Chang et al..$^{(32)}$ \\
\hline 11 & Eriodictyol & Flavanone & Lemons, rosehips & Hvattum $^{(46)}$ \\
\hline 12 & Fisetin & Flavonol & $\begin{array}{l}\text { Strawberries, apples, persimmons, onions, } \\
\text { cucumbers }\end{array}$ & Sahu et al. ${ }^{(47)}$ \\
\hline 13 & Theaflavin & Catechins & Tea leaves, black tea, oolong tea & Leung et $a l^{(48)}$ \\
\hline 14 & Peonidin & Anthocyanidin & $\begin{array}{l}\text { Cranberries, blueberries, plums, grapes, cherries, } \\
\text { sweet potatoes }\end{array}$ & Truong et al. ${ }^{(49)}$ \\
\hline 15 & Diosmetin & Flavone & Vetch & Andreeva et al. ${ }^{(50)}$ \\
\hline 16 & Tricin & Flavone & Rice bran & Cai et al. ${ }^{(51)}$ \\
\hline 17 & Biochanin & Isoflavone & $\begin{array}{l}\text { Red clover, soya, alfalfa sprouts, peanuts, chickpeas } \\
\text { (Cicer arietinum), other legumes }\end{array}$ & Medjakovic \& Jungbauer ${ }^{(52)}$ \\
\hline 18 & Hesperidin & Flavanone & $\begin{array}{l}\text { Bitter orange, petit grain, orange, orange juice, lemon, } \\
\text { lime }\end{array}$ & $\begin{array}{l}\text { National Agricultural Library }{ }^{(53)} \text {; Khan } \\
\text { et al. }{ }^{(34)}\end{array}$ \\
\hline 19 & Epicatechin & Flavan-3-ols & Milk, chocolate, commercial, reduced fat & Arts et al. ${ }^{(54)}$ \\
\hline 20 & Myricetin & Flavonols & Vegetables, fruits, nuts, berries, tea, red wine & Ross \& Kasum ${ }^{(55)}$; Basli et al. ${ }^{(56)}$ \\
\hline 21 & Taxifolin & Flavanonol & Citrus fruits & Grayer \& Veitch ${ }^{(57)}$; Kawaii et al. ${ }^{(58)}$ \\
\hline 22 & Kaempferol & Flavonols & $\begin{array}{l}\text { Apples, grapes, tomatoes, green tea, potatoes, } \\
\text { onions, broccoli, Brussels sprouts, squash, } \\
\text { cucumbers, lettuce, green beans, peaches, } \\
\text { blackberries, raspberries, spinach }\end{array}$ & $\begin{array}{l}\text { Calderon-Montaño et al. }{ }^{(59)} ; \text { Liu }^{(60)} ; \mathrm{Kim} \\
\& \text { Choi }\end{array}$ \\
\hline 23 & Luteolin & Flavones & $\begin{array}{l}\text { Celery, broccoli, green pepper, parsley, thyme, } \\
\text { dandelion, perilla, chamomile tea, carrots, olive oil, } \\
\text { peppermint, rosemary, navel oranges, oregano }\end{array}$ & Kayoko et al. ${ }^{(62)}$; López-Lázaro ${ }^{(63)}$ \\
\hline 24 & Apigenin & Flavones & Milk, chocolate, commercial, reduced fat & Hertog et al. ${ }^{(26)}$ \\
\hline
\end{tabular}

The enzyme exists in two isoforms, COX-1 and COX-2. COX-1 is a constitutive enzyme and is responsible for the supply of prostaglandins which maintain the integrity of the gastric mucosa and provide adequate vascular homeostasis whereas COX-2 is an inducible enzyme and is expressed only after an inflammatory stimulus ${ }^{(67)}$. The function of COX-2 is to synthesise prostaglandins for the induction of inflammation and pain ${ }^{(68)}$. The studies done by using in silico methods on the binding modes of flavonoids with COX-2 explored that some flavonols and flavones containing a 2, 3-double bond may act as preferential inhibitors of COX $-2^{(69)}$. These observations were found for the flavonol, flavone, and flavanone or isoflavone classes. This discovery led to the development of selective COX-2 inhibitors which are a class of compounds with good anti-inflammatory activity and reduced gastrointestinal side effects. The commercially available flavonoids like silbinin, galangin, scopoletin, hesperitin, genistein, daidzein, esculatin, taxifolin, naringenin and celecoxib were also evaluated for COX-inhibitory activity ${ }^{(70)}$. The selected flavonoids showed higher binding energy ranging between -8.77 to $-6.24 \mathrm{kcal} / \mathrm{mol}(-36.69$ to $-26.11 \mathrm{~kJ} / \mathrm{mol})$ when compared with that of the standard $(-8.30 \mathrm{kcal} / \mathrm{mol} ;-34.73$ $\mathrm{kJ} / \mathrm{mol}$ ) which led to the development of potent COX inhibitors for the treatment of inflammation. Madeswaran et al. ${ }^{(70)}$ evaluated the COX-inhibitory activity of flavonoids using in silico docking studies. In this perspective, they used flavonoids like farobin-A, gericudranin-B, glaziovianin- $A$, rutin and xanthotoxin. Their docking results showed that all the selected flavonoids contributed better aldose reductase inhibitory activity because of their structural parameters. Hence, further deeper studies could develop potent aldose reductase inhibitors for the treatment of diabetes. Madeswaran et al. ${ }^{(71)}$ also reported in silico docking studies of lipoxygenase-inhibitory activity of commercially available flavonoids. In this perspective, they selected flavonoids like aromadedrin, eriodictyol, fisetin, homoeriodictyol, pachypodol, rhamnetin, robinetin, tangeritin, theaflavin and azelastine for investigation. It was observed that all the selected flavonoids contributed to lipoxygenase-inhibitory activity because of their structural parameters and the whole analysis could lead to the further 
development of potent drugs for the treatment of inflammation. Wu et al. ${ }^{(72)}$ worked on antiplatelet effects and selective binding of COX with flavonoids and lignans by using the molecular docking method. The flavonoids considered were ginkgetin, Taiwan-homo-flavone A, Taiwan-homo-flavone B and Taiwan-homo-flavone $\mathrm{C}$ and eight known lignans justici$\operatorname{din} \mathrm{B}$, justicidin $\mathrm{C}$, justicidin $\mathrm{D}$, chinensinaphthol methyl ether, procumphthalide $A$, procumbenoside $A$ and ciliatosides $\mathrm{A}$ and $\mathrm{B}$ from medicinal herbal plants, Cephalotaxus wilsoniana and Justicia species, respectively. Out of these flavonoids ginkgetin, Taiwan-homo-flavone $\mathrm{C}$, justicidin $\mathrm{B}$ and justicidin $\mathrm{D}$ were found to be effective for antiplatelet effects.

\section{Steroid-genesis modulators}

Abyssinones and related flavonoids can be used as potential steroid-genesis modulators against three enzymes $3 \beta$ hydroxysteroid dehydrogenase (HSD), 17 $\beta$-HSD and aromatase of the steroid-genesis pathway ${ }^{(73)}$. The virtual screening experiment indicated higher affinity for flavonones than their respective chalcones. The flavonones possess consistent binding affinity to all the three enzymes used and are better steroidogenesis modulators in hormone-dependent cancer.

\section{Xanthine oxidase modulators}

$\mathrm{XO}$ catalyses the conversion of hypoxanthine to xanthine and subsequently xanthine to uric acid. The increase of uric acid level in blood serum, which is called hyperuricaemia, can lead to major complications such as gout and kidney stones ${ }^{(74,75)}$. Alnajjar ${ }^{(76)}$ worked on natural flavonoids towards the discovery of a potential XO inhibitor. Licoisoflavone-A extracted from the roots of Glycyrrbiza glabra (liquorice) showed the most potent activity in the inhibition of XO. Umamaheswari et al. ${ }^{(77)}$ evaluated XO-inhibitory activity of flavonoids using in silico docking studies. The flavonoids butein, fisetin, diosmetin, tricetin, genistein, tricin, vitexycarpin, herbacetin, biochanin, rhamnetin, isorhamnetin, robinetin, peonidin and okanin were studied and it was found that all flavonoids exerted inhibition activity. The presence of a benzopyran ring in their basic nucleus would have contributed to its XO-inhibitory activity. This molecular docking analysis may further lead to the development of potent XO inhibitors for the prevention and treatment of gout and related inflammatory ailments. New drugs for the inhibition of the enzyme aldose reductase are in development and efforts are being made for their preclinical and clinical evaluation.

A novel approach emphasising the significance of natural products as a prime solution to unanswered questions like the treatment of the 'silent killer' 'polycystic kidney disease' (PKD) has been investigated ${ }^{(78)}$. The key protein, namely cystic fibrosis transmembrane conductance regulator (which is responsible for $\mathrm{PKD}$ ), and its mutated three-dimensional structure were subjected to molecular docking and in silico toxicity studies with flavonoids from vegetable sources. The outcome indicated the possible application of flavonoids from vegetable sources as potential and natural therapeutic agents to combat PKD.
Lin et al. ${ }^{(79)}$ carried out in vitro kinetic studies of different flavonoids as inhibitors with various xanthine concentrations. In vitro studies and kinetic measurements of different flavonoids and various concentrations of xanthine were carried out ${ }^{(79)}$. Four potent XO inhibitors were found in $95 \%$ ethanolic $(\mathrm{v} / \mathrm{v})$ gnaphalium affine extract. Among them, the flavone eupatilin exhibited the strongest inhibitory effect on XO compared with allopurinol, a known synthetic XO inhibitor. Apigenin, luteolin and 5-hydroxy-6, 7, 3', 4'-tetramethoxyflavone also contributed to the inhibitory effect of gnaphalium affine extract on $\mathrm{XO}$ activity. This study provides a rational basis for the traditional use of gnaphalium affine against gout. The study on in vitro XO-inhibitory activity of the aglycone hesperetin and its glycosylated forms (hesperidin and G-hesperidin) and their effects on the plasma lipid profile and the oxidative-antioxidative system has been carried out in rats ${ }^{(80)}$. The concentrations of the major conjugated metabolites in rat plasma after oral administration of these compounds were also determined. It has been reported that hesperetin was found to have a stronger XO-inhibitor activity than the glycosylate derivatives.

\section{Countering antibiotic resistance}

$\beta$-Ketoacyl acyl carrier protein synthase III (KAS III), which initiates fatty acid synthesis in bacteria, is a key target enzyme to overcome the antibiotic resistance problem. Lee et al. ${ }^{(81)}$, while working on the known flavonoid inhibitors of $\beta$-KAS III against the methicillin-resistant bacteria Staphylococcus aureus, found that flavonoids such as naringenin $\left(5,7,4^{\prime}\right.$-trihydroxyflavanone) and eriodictyol $\left(5,7,3^{\prime}, 4^{\prime}\right.$-tetrahydroxyflavanone) are potent antimicrobial inhibitors of Staphylococcus aureus KAS III. Ganugapati et al. ${ }^{(82)}$ worked on in silico modelling and docking studies of a superbug enzyme, namely New Delhi metallo- $\beta$-lactamase-1 (NDM-1), which is an enzyme found in Escherichia coli. It has been reported that this enzyme belongs to a B1 subclass of metallo $\beta$-lactamases and is known to induce resistance to standard intravenous antibiotics. Similar studies were carried out on inhibition of NDM-1 in superbugs by flavonoids using the technique of in silico molecular docking ${ }^{(83)}$. At present, there are no effective antibiotics against the NDM-1-positive pathogen and therefore this study provides clues to investigate the molecular basis of extended antibiotic resistance of NDM-1 and then accelerate the search for new antibiotics against the NDM-1-positive strain in clinical studies. Quercetin and its analogue penta- $O$-ethylquercetin were found to be potential inhibitors of NDM-1.

\section{Disease-combating activity}

Ganugapati et al. ${ }^{(84)}$ studied green tea flavonoids as insulin mimetics. Diabetes mellitus is a metabolism disorder where glucose, a principal source of energy, cannot enter the cells due to deficiency of insulin. The study suggested that epicatechin acts as an insulin receptor activator and reduces the harmful effects of diabetes. Lu \& Chong $^{(85)}$ carried out the computational work to predict the binding modes of flavonoid derivatives with the neuraminidase of the 2009 haemagglutinin 
1 neuraminidase (H1N1) influenza virus. They employed molecular dynamics simulation techniques to optimise the 2009 H1N1 influenza neuraminidase X-ray crystal structure. All the twenty flavonoid derivatives were found to be satisfactory in binding and inhibiting the activity of the virus. These findings may help to develop a potential drug form of the flavonoid derivatives for the treatment of H1N1 influenza disease. Cardenas et al. ${ }^{(86)}$ showed through a study on mice that apigenin, a dietary flavonoid, exerts immune-regulatory activity. The study carried out on NF- $\mathrm{KB}$ luciferase transgenic mice showed effective modulation of NF- $\mathrm{\kappa B}$ with no effect on the rate of cell death, a decrease in lipopolysaccharide-induced apoptosis in lungs, and infiltration of inflammation, leading to re-establishment of normal lung architecture. These effects indicate the immune-regulatory roles of flavonoids. Kim et al. ${ }^{(87)}$ reported that a flavonoid-rich diet is associated with a reduced risk of CVD. The study focused on individual as well as total flavonoid diet effects. Higher flavonoid intake was found to be associated with the improved CVD risk factors. Mulvihill et al. ${ }^{(88)}$ focused on the ability of citrus flavonoids to modulate lipid metabolism and other metabolic parameters related to the metabolic syndrome. This is one of the recent trends which have focused on citrus flavonoids as potential therapeutic agents for the treatment of metabolic dysregulation. The observational studies done by Hügel et al. ${ }^{(89)}$ indicated that dietary flavonoids are associated with a decreased risk of hypertension and CVD. A diet rich in all flavonoid classes through herbs and beverages improves vascular health leading to a reduced risk of diseases. It has been observed that the consumption of them is associated with improvement in endothelial function via vascular endothelial nitric oxide synthase and protein kinase B (Akt) activation. The effect of regular quercitin intake on blood pressure in overweight and obese patients with pre-hypertension and stage I hypertension was studied in seventy patients. Ambulatory blood pressure and office blood pressure were measured. It was observed that the blood pressure level was reduced in patients with hypertension ${ }^{(90)}$.

Recently it has been reported that an apple of the type pelingo is rich in food components that can markedly inhibit in vitro tumorigenesis and the growth of human breast cancer cells ${ }^{(91)}$. It was observed that pelingo juice induced cell accumulation in the G2/M phase of the cell cycle, autophagy, inhibition of extracellular signal-regulated kinases $1 / 2$ (ERK1/2) activity and an increase in lipidated microtubuleassociated protein-1 light chain-3 $\beta$ (LC3B). Hence it could be used as a source of bioactive compounds with potential chemopreventive activity. Through the review of randomised controlled trials, it has been observed that intake of purified and extract forms of anthocyanins leads to significant improvement in LDL-cholesterol with no adverse effects ${ }^{(92)}$. An in vivo study model of rats was used to examine the effect of fenugreek seeds on renal pathology in alcoholics ${ }^{(93)}$. The different concentrations of seeds and their exerted effects were checked through transmission electron microscopy. The results showed reduction in cell deterioration and improvement in renal morphology and function. A tannin-rich extract obtained from the pinhão (Araucaria angustifolia) seed was found to inhibit $\alpha$-amylase ${ }^{(94)}$. The same extract was also examined for inhibition of pancreatic lipase. An effective level of inhibition was observed for pancreatic lipase also. The extract also showed a significant reduction in TAG levels in mice. These results indicate that tannin can be used as a potential molecule for anti-obesity ${ }^{(95)}$. An extract of mixed polyphenolic compounds of grape seeds was found to comprise the ability to inhibit the aggregation and oligomerisation of $\beta$-amyloid in vitro and also improve the behavioural deficits in a mouse model of $\mathrm{AD}^{(96)}$. Paris $e t \mathrm{al}^{(97)}$ worked on flavonoids which lower Alzheimer's amyloid protein $(A \beta)$ production via a nuclear factor $\kappa$-light-chain-enhancer of activated $\mathrm{B}$ cells $(\mathrm{NF}-\mathrm{kB})$-dependent mechanism. It is well known that $\mathrm{AD}$ is due to the accumulation of $A \beta$ peptides and the presence of neurofibrillary tangles in the brain ${ }^{(98,99)}$. A $\beta$ is believed to play an important role in $\mathrm{AD}$ and it has been shown that certain flavonoids such as genistein, quercetin, taxifolin, kaemferol, luteolin, apigenin, daidzein, aminogeneistein, and $\alpha$ - and $\beta$-napthofalvone can affect $A \beta$ production. Recently, it was suggested that the $A \beta$-lowering properties of flavonoids are mediated by a direct inhibition of $\beta$ active site cleavage enzyme-1 (BACE-1) activity, the rate-limiting enzyme responsible for the production of $A \beta$ peptides ${ }^{(97)}$. It has been reported that a strong correlation exists between the inhibition of NF- $\kappa \mathrm{B}$ activation by flavonoids and their $\mathrm{A} \beta$-lowering properties, suggesting that flavonoids inhibit $A \beta$ production

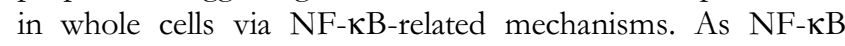
has been shown to regulate BACE-1 expression, it has been concluded that NF- $\mathrm{kB}$-lowering flavonoids inhibit BACE-1 transcription in human neuronal cells. Shimmyo et al. ${ }^{(100)}$, while working on structure-activity relationships in cell-free, cell-based and in silico modes revealed novel pharmacophore features of flavonoids. Their results contributed to the development of new BACE-1 inhibitors by certain natural flavonoids (myricetin, quercetin, kaempherol, morin, apigenin) for the treatment of AD. Swaminathan $e a l^{(101)}$ worked on a series of natural and synthetic flavones and flavonols to explore their activity against radio ligand binding at human cloned muscarinic receptors. It has been mentioned that muscarinic acetylcholine receptor-active compounds have potential to treat $\mathrm{AD}^{(102)}$. Their findings indicated that there are several flavonoid compounds which possess competitive binding affinity, comparable with that of acetylcholine. Molecular modelling studies suggested that the compounds bind to the orthosteric site of the receptor, mainly through non-polar interactions. Further, it is mentioned that due to limitations in the docking and scoring functions used, no significant energy differences were observed for binding of the active compounds compared with the inactive compounds. These results give an indication of the potential of flavonoid compounds for the treatment of $\mathrm{AD}$.

\section{Flavonoid mechanisms}

Almost every group of flavonoids has a capacity to act as antioxidants. It has been reported that the flavones and catechins seem to be the most powerful flavonoids for protecting the body against reactive oxygen species. Body cells and tissues 
are continuously threatened by the damage caused by free radicals and reactive oxygen species, which are produced during normal oxygen metabolism or are induced by exogenous damage ${ }^{(103,104)}$. The mechanisms and the sequence of events by which free radicals interfere with cellular functions are not fully understood, but one of the most important events seems to be lipid peroxidation, which results in cellular membrane damage. This cellular damage causes a shift in the net charge of the cell, changing the osmotic pressure, leading to swelling and eventually cell death. Free radicals can attract various inflammatory mediators, contributing to a general inflammatory response and tissue damage. To protect themselves from reactive oxygen species, living organisms have developed several effective mechanisms ${ }^{(105)}$. The antioxidant defence mechanisms of the body include not only the enzymes such as superoxide dismutase, catalase and glutathione peroxidase, but also non-enzymic counterparts such as glutathione, ascorbic acid and $\alpha$-tocopherol. The increased production of reactive oxygen species during injury results in consumption and depletion of the endogenous scavenging compounds. Flavonoids may have an additive effect to the endogenous scavenging compounds ${ }^{(106)}$. Codorniu-Hernández et al. ${ }^{(107)}$ carried out docking studies to understand flavonoid-protein interactions. The results indicated that hydrophilic amino acid residues demonstrate high-affinity interactions with flavonoid molecules, as was predicted by the theoretical affinity order. The docking modes among catechin molecules and four proteins (human serum albumin, transthyretin, elastase and renin) are also supporting this information. The theoretical affinity order among flavonoids and amino acid residues seems to have great applications in the theoretical predictions of flavonoid-protein interactions as a high-quality approach to understand the biological activity of flavonoids.

\section{Radical scavenging}

Flavonoids can prevent injury caused by free radicals in various ways and one way is the direct scavenging of free radicals. Flavonoids are oxidised by radicals, resulting in a more stable, less-reactive radical. In other words, flavonoids stabilise the reactive oxygen species by reacting with the reactive compound of the radical. Because of the high reactivity of the hydroxyl group of the flavonoids, radicals are made inactive, as explained in the following equation as given by Korkina \& Afanasev ${ }^{(108)}$ :

$$
\text { Flavonoid }(\mathrm{OH})+\mathrm{r}(\mathrm{O})+\mathrm{RH}
$$

where $\mathrm{R}$ is a free radical and $\mathrm{O}$ is an oxygen free radical. Hanasaki et al. ${ }^{(109)}$ found that some of the flavonoids can directly scavenge superoxides, whereas other flavonoids can scavenge the highly reactive oxygen-derived radical called peroxynitrite. They found that flavonoids such as epicatechin and rutin are powerful radical scavengers and the scavenging ability of rutin may be due to its inhibitory activity on the enzyme XO. Kerry \& Abbey ${ }^{(110)}$ reported that by scavenging radicals, flavonoids can inhibit LDL oxidation in in vitro studies. They further mentioned that this action protects the LDL particles and, theoretically, flavonoids may have preventive action against atherosclerosis.

\section{Xanthine oxidase inhibition}

Sanhueza et al..$^{(111)}$ worked on changes in the xanthine dehydrogenase:XO ratio in the rat kidney subjected to ischaemia-reperfusion stress and also studied the preventive effect of some flavonoids. They mentioned that the XO pathway is an important route in the oxidative injury to tissues, especially after ischaemia-reperfusion. Xanthine dehydrogenase is the form of the enzyme present under physiological conditions, but its configuration is changed to $\mathrm{XO}$ during ischaemic conditions. $\mathrm{XO}$ is a source of oxygen free radicals. In the reperfusion phase (reoxygenation), $\mathrm{XO}$ reacts with molecular oxygen, thereby releasing superoxide free radicals. Two flavonoids, quercetin and silibin, were found to inhibit XO activity, thereby resulting in decreased oxidative injury ${ }^{(112,113)}$. Cos et al. ${ }^{(114)}$ worked on structure-function relations in which the flavonoid luteolin (tetrahydroxyflavone) was reported to be the most potent inhibitor of $\mathrm{XO}$.

\section{Anti-inflammation}

Nijveldt $e t$ al. ${ }^{(106)}$ reported about how immobilisation of leucocytes in the blood vascular system can damage tissues through the release of oxidants and inflammators. They mentioned in their paper that the immobilisation and firm adhesion of leucocytes to the endothelial wall lead to the formation of oxygenderived free radicals and also release of cytotoxic oxidants and inflammatory mediators. Under normal conditions, leucocytes move freely along the endothelial wall. However, during ischaemia and inflammation, various endothelium-derived mediators and complement factors may cause adhesion of the leucocytes to the endothelial wall, thereby immobilising them and stimulating degranulation of the neutrophil. As a result, oxidants and inflammatory mediators are released, resulting in injury to tissues. Friesenecker et al. ${ }^{(115)}$, while working on the oral administration of a purified micronised flavonoid fraction, found that the flavonoids suppresses leucocyte adhesion in ischaemia-reperfusion injury in hamsters. The decrease in the number of immobilised leucocytes by flavonoids may be related to the decrease in total serum complement and is a protective mechanism against inflammationlike conditions associated with reperfusion injury ${ }^{(16)}$. Some flavonoids have been shown to inhibit degranulation of neutrophils without affecting superoxide production ${ }^{(117)}$.

Compared with the research work done on the antioxidant capacities of flavonoids, there has been relatively little research on other possible mechanisms. One such mechanism by which flavonoids act is through interaction with various enzyme systems. Furthermore, some effects may be a result of a combination of radical scavenging and an interaction with enzyme functions ${ }^{(107)}$. Alcaraz \& Ferrandiz ${ }^{(118)}$, while working on anti-inflammatory activity and the inhibition of arachidonic acid metabolism by flavonoids, reported that flavonoid inhibit the metabolism of arachidonic acid through the enzyme pathway. This feature gives flavonoids anti- 
inflammatory and anti-thrombogenic properties. The release of arachidonic acid is a starting point for a general inflammatory response and neutrophils containing lipoxygenase create chemotactic compounds from arachidonic acid.

\section{Combating neurodegenerative diseases}

The recent studies on different plant metabolites have shown that flavonoids may perform a key role in enzyme and receptor systems of the brain, exerting significant effects on the central nervous system, like prevention of the neurodegeneration associated with $\mathrm{AD}$ and Parkinson's disease ${ }^{(15,119)}$. Flavonoids are capable of inhibiting enzymes, as there exist strong reports about inhibitory enzymes such as aldose reductase, XO, phosphodiesterase, $\mathrm{Ca}^{2+}$ ATPase, lipoxygenase and COX in preventive neurodegenerative diseases.

Considerable work has been carried out to search suitable and new flavonoids for therapeutic use in $\mathrm{AD}$ by using the technique of molecular docking. Hu et al. ${ }^{(120)}$ have designed a new series of flavonoids, evaluated them and discovered potent AChE inhibitors. Most of them showed more potent inhibitory activities against $\mathrm{AChE}$ than rivastigmine, an $\mathrm{AD}$ drug. Further, it was mentioned that the isoflavone skeleton would be a promising structural template for the development of novel AChE inhibitors. Khan ${ }^{(34)}$ has examined AChE- and BChE-inhibitory activities of four flavonoid derivatives quercetin, rutin, kaempferol galactoside and macluraxanthone. Out of four flavonoids, macluraxanthone displayed a concentration-dependent inhibition of AChE and BChE. A number of flavonoids were studied to lower Alzheimer's $A \beta$ production using molecular docking studies. It has been reported that there exists a strong correlation between flavonoids and inhibitions of NF- $\mathrm{KB}$-related mechanisms. While doing work on the molecular docking of flavones as BACE-1 inhibitors, it has been found that the flavonoids potently inhibit BACE-1 activity through the interactions of flavonoids with the BACE-1 catalytic centre ${ }^{(100)}$.

\section{Functions and applications of flavonoids}

Plants produce a vast and diverse assortment of organic compounds, the great majority of which do not appear to participate directly in growth and development. These substances, traditionally referred to as secondary metabolites (flavonoids), often are differentially distributed among limited taxonomic groups within the plant kingdom ${ }^{(121)}$. The flavonoids are categorised in different classes as alkaloids, terpenoids and phenolics. Flavonoids carry out a number of protective functions in the human body (Fig. 3). Many flavonoids have evolved as bioactive compounds that interfere with nucleic acid or proteins and show antimicrobial or insecticidal and pharmacological properties. Flavonoids are therefore of interest in medicine as therapeutics and at the same instance in agriculture as pesticides ${ }^{(122)}$. In vitro technology has given new insight to explore the potency of plant cell tissue culture to produce the same valuable chemical compounds as those of the parent plant ${ }^{(123)}$. The advancement in plant tissue culture methods for flavonoid production has bloomed beyond expectations ${ }^{(124)}$. Plant tissue culture is an aseptic technique whereby proper manipulation of the nutrients, culture conditions, and phyto-hormone supply, one may be able to produce the desired quality and quantity of plants as well as metabolites. With the culture of differentiated cells it is possible to obtain production of the desired compounds in levels comparable with that of the plant. Flavonoids are associated with a broad spectrum of health-promoting effects. They are an indispensable component in a variety of nutraceutical, pharmaceutical, medicinal and cosmetic applications. This is attributed to their antioxidative ${ }^{(125)}$, anti-inflammatory ${ }^{(126)}$, anti-mutagenic ${ }^{(127)}$ and anti-carcinogenic ${ }^{(128)}$ properties coupled with their capacity to modulate key cellular enzyme functions ${ }^{(129)}$. Flavonoids act in plants as antioxidants, antimicrobials, photoreceptors, visual attractors, feeding repellents, and for light screening. Many studies have suggested that flavonoids exhibit biological activities, including anti-allergenic, antiviral, anti-inflammatory and vasodilating actions. However, most interest has been devoted to the antioxidant activity of flavonoids which is due to their ability to reduce free radical formation and to scavenge free radicals. The capacity of flavonoids to act as antioxidants in vitro has been the subject of several studies in the past years, and important structure-activity relationships of the antioxidant activity have been established ${ }^{(125,130)}$. Ren et al. ${ }^{(130)}$, in their paper on flavonoids and anticancer agents, gave the major molecular mechanisms of actions in different situations. In preventing carcinogens they mentioned that flavonoids exert their effects on cytochrome P450 to inhibit the activities of certain P450 isozymes which are responsible for the production of a number of procarcinogens. Another mechanism of action they reported is that flavonoids help in the production of metabolising enzymes such as gluthione- $S$-transferase, quinone reductase and uridine 5-diphospho-glucuronyl transferase by which carcinogens are detoxified and thus eliminated from the body. This would also help in preventing the chemotherapy effect of flavonoids against carcinogens.

A number of studies have been carried out on properties of antioxidant in relation to different flavonoids and these studies emphasised that the flavonoids can be used as potential drugs to prevent oxidative stresses ${ }^{(131-136)}$. Antioxidants are compounds that protect the cells against the oxidative effect of reactive oxygen species, and the impaired balance between these reactive oxygen species and antioxidants results in oxidative stress. The oxidative stress may lead to cellular damage which is related to various health ailments such as diabetes, cancer, CVD, neurodegenerative disorders and ageing. Oxidative stress can also damage many biological molecules and proteins and DNA molecules are significant targets of cellular injury. Antioxidants interfere with radical-producing systems and increase the function of endogenous antioxidants, protecting the cells from damage by these free radicals ${ }^{(125)}$. Pietta ${ }^{(137)}$ reviewed the current knowledge on structural aspects and in vitro antioxidant capacity of most common flavonoids as well as in vitro antioxidant activity and effects on endogenous antioxidants. Flavonoids have been found to be very effective in preventing lipid peroxidation and lipid peroxidation is responsible for various diseases such as atherosclerosis, diabetes, hepatotoxicity and inflammation, along with 


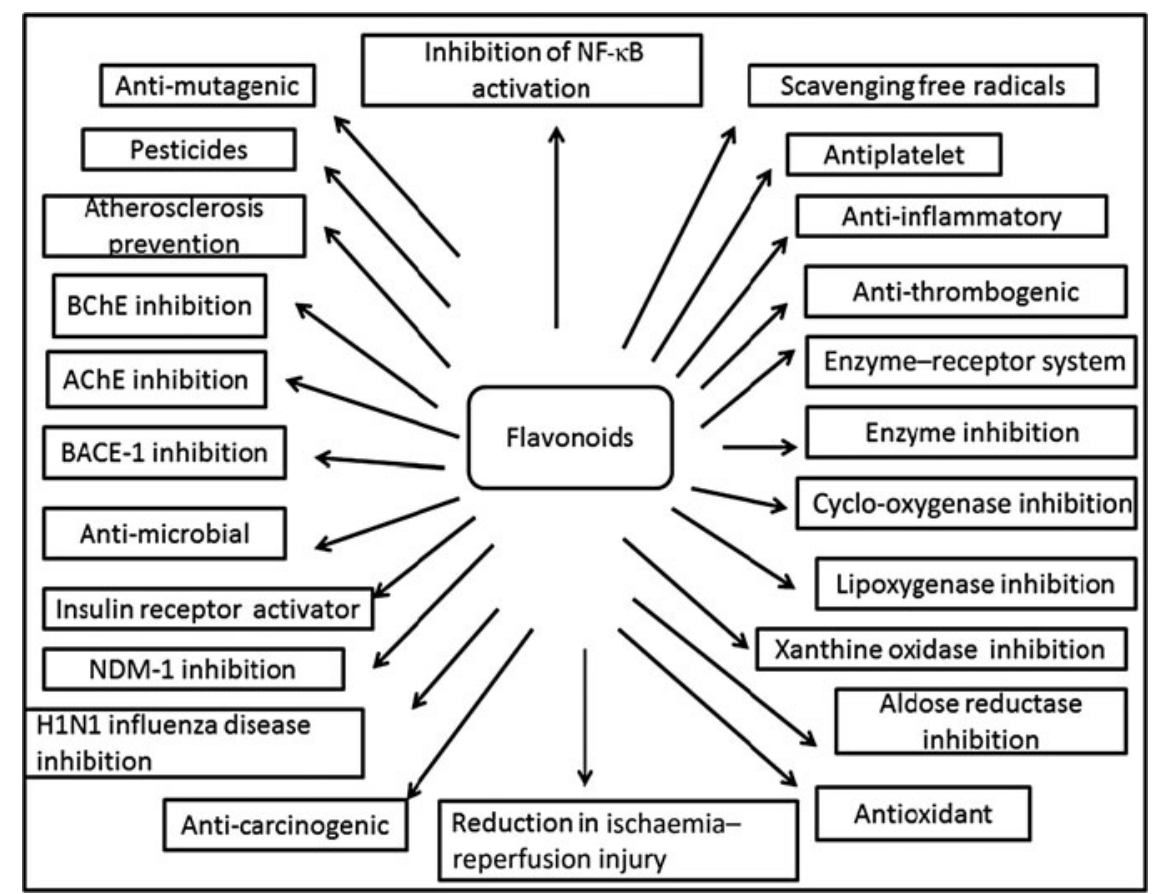

Fig. 3. Cumulative representation of roles of flavonoids in various bioactivities, human health and agriculture. BChE, butyrylcholinesterase; AChE, acetylcholinesterase; BACE-1, $\beta$ active site cleavage enzyme-1; NDM-1, New Delhi metallo- $\beta$-lactamase-1; H1N1, haemagglutinin 1 neuraminidase 1.

ageing $^{(138-140)}$. Studies have indicated that quercetin helps to suppress lipid peroxidation ${ }^{(141)}$. In addition to quercetin, there are other flavonoids such as myricetin, quercetrin and rutin which help to inhibit the production of superoxide radicals ${ }^{(103,104)}$.

Flavonoids have also been recognised for their antimicrobial activity and many researchers have isolated and identified the structures of flavonoids having properties of antifungal, antiviral and antibacterial activity. Because of this property, many flavonoids are now being used extensively in the fields of nutrition, food safety and health. The antiviral effect of flavonoids has been shown by Wang et al. ${ }^{(142)}$, particularly in therapy for viral infection. Flavonoids such as quercetin, naringin, hesperetin and catechin possess a variable degree of antiviral activity. They affect the replication and infectivity of certain RNA and DNA viruses ${ }^{(143)}$. Quercetin and apigenin are among the most studied flavonoids which have been known to exhibit antibacterial activities ${ }^{(144)}$. $\mathrm{Li} \& \mathrm{Xu}^{(145)}$ have reported that quercetin extracted from lotus leaves may be a promising antibacterial agent for periodontitis.

Some flavonoids show hormone-like activities and they bear a resemblance to steroid hormones, particularly with oestrogen. Such flavonoids are present in fruits and vegetables, tea, red wine and cereals ${ }^{(125)}$. Hormone-like steroids are well known in protection against various chronic diseases, especially oestrogen, which has neuroprotective effects on the brain. A number of flavonoids such as genistein, daidzein and equol have been studied to assess their oestrogenic activity in clinical trials. The studies determined their potential for treatment of various chronic diseases such as cancer, cardiovascular disorders and osteoporosis ${ }^{(146,147)}$. From their studies it is found that the flavonoid genistein has the most promising effect in preventing postmenopausal bone loss in women. A number of flavonoids of dietary significance have been shown to impart beneficial impact on parameters associated with atherosclerosis, including lipoprotein oxidation, blood platelet aggregation and cardiovascular reactivity ${ }^{(148,149)}$. Comalada et al. ${ }^{(150)}$ reviewed the effects of flavonoids, particularly quercetin, on a variety of inflammatory processes and immune functions and it has been shown that certain flavonoids help in inhibiting the initial process of inflammation and improve the immune system. Anti-inflammatory activity using flavonoids and tannins from the leaves of the plant Spilanthes paniculata has been recently reported ${ }^{(126)}$. Anticancer effects of flavonoids such as tangeritin, 3-hydroxyflavone, 3',4'-dihydroxyflavone, 2',3'-dihydroxyflavone, fisetin, apigenin, luteolin daidzein and genistein have been carried out by a number of researchers ${ }^{(151-154)}$. Ren et al. ${ }^{(130)}$ and Huang et al. ${ }^{(155)}$, while working on natural phenolic compounds and their potential use for cancer prevention, reported that various flavonoids such as tannins, stilbenes, curcuminoids, coumarins, lignans, quinones and other flavonoids have chemopreventive properties and also contribute to induce apoptosis by arresting the cell cycle, regulating carcinogen metabolism and ontogenesis expression. While explaining the possible mechanism of flavonoids in cancer prevention they further mentioned that the flavonoids have complementary and overlapping mechanisms of action including antioxidant activity and scavenging free radicals, modulation of carcinogen metabolism, regulation of gene expression on oncogenes and tumour-suppressor genes in cell proliferation and differentiation, induction of cell cycle arrest and apoptosis, modulation of enzyme activities in detoxification, oxidation and reduction, anti-inflammatory properties and action on other possible targets. Flavonoids and their effect of protection of the central nervous system are concerned particularly with those related 
to neurodegenerative disease caused by the combined effect of oxidative stress, inflammation and transition metal accumulation; a good amount of information is available. Alzheimer's and related dementias are among some of the major disorders of neurodegeneration. Flavonoids, like flavonols, are associated with lower population rates of dementia ${ }^{(156)}$. Similarly, Hwang \& Yen ${ }^{(157)}$ and Jager \& Saaby ${ }^{(119)}$ suggested that citrus flavanones such as hesperidin, hesperetin and naringenin could traverse the blood-brain barrier and may play an effective role in the intervention for neurodegenerative diseases. The role of flavonoids in antidiabetic activity and anti-ageing has also been reported $^{(158-161)}$.

\section{Future research and development programmes}

Flavonoids have received much attention in the literature over the past 10 years and a variety of potential beneficial effects have been elucidated. However, a number of studies carried out involved in vitro and in silico studies. Therefore, further studies are needed so that the usefulness of flavonoids in the diet could be improved for better human health. The study of flavonoids is complex because of the heterogeneity of the different molecular structures and the scarcity of data on bioavailability. Furthermore, insufficient methods are available to measure oxidative damage in vivo and the measurement of objective end points remains difficult. There is a need to improve analytic techniques to allow the collection of more data on absorption and excretion. Data on the long-term consequences of chronic flavonoid ingestion are especially scarce. A number of reports have emphasised that molecular docking studies are required to identify the potential molecules of flavonoids for their usage in the treatment of various ailments in the human health system. The interactions of flavonoids with receptor molecules during the treatment of acute and chronic diseases are an important area of future research. More and more research is needed to discover new flavonoids from nature's bounty so that this will replace the use of synthetic medicines which are harmful to the body. In this context there is a need of research and development programmes involving in vivo studies which will give a hopeful and safe picture for the future. Currently, the intake of fruit, vegetables and beverages containing flavonoids is recommended, although it is too early to make recommendations on daily flavonoid intakes.

\section{Acknowledgements}

We sincerely thank Shri. Ankushrao Kadam, Secretary, Mahatma Gandhi Mission Trust, Aurangabad, Maharashtra, India, for providing all the facilities during the preparation of the present paper and for encouragement.

The first author (A. N. P.) is presently working as Assistant Professor in the MGM Institute of Biosciences \& Technology and carrying out her doctoral research studies on some of the Indian medicinal herbs and their ingredients (may be flavonoids) and their impact on treatment of AD. She has already published a paper on $\mathrm{AD}$ and therapeutics in one international pharmaceutical journal. She has also carried out computational studies for the identification of potential candidate molecules from the natural source of plants. The second author (A. D. D.) is an emeritus professor in the Institute of Biosciences \& Technology and co-guide of the first author. His main area of research is on physiology and neuro-endocrinological aspects in fish and shellfish. He has published 150 research papers in journals of national and international repute and published ten books mostly related to physiology and biotechnology. The third author (S. R. C.) is an assistant professor in the Department of Bioengineering at Birla Institute of Technology, Mesra. Her research is mostly related to molecular aspects of plant ingredients and their impact on various therapeutics. Her research area is in plant tissue culture also.

There are no conflicts of interest.

\section{References}

1. Burak M \& Imen Y (1999) Flavonoids and their antioxidant properties. Turkiye Klin Tip Bil Derg 19, 296-304.

2. Ovando C, Hernandez D, Hernandez E, et al. (2009) Chemical studies of anthocyanins: a review. Food Chem 113, 859-871.

3. Lee Y, Yuk D, Lee J, et al. (2009) Epigallocatechin-3-gallate prevents lipopolysaccharide-induced elevation of $\beta$-amyloid generation and memory deficiency. Brain Res 1250, 164-174.

4. Metodiewa D, Kochman A \& Karolczak S (1997) Evidence for antiradical and antioxidant properties of four biologically active $N, N$, diethylaminoethyl ethers of flavanone oximes: a comparison with natural polyphenolic flavonoid (rutin) action. Biochem Mol Biol Int 41, 1067-1075.

5. Hayashi T, Sawa K, Kawasaki M, et al. (1988) Inhibition of cow's milk xanthine oxidase by flavonoids. J Nat Prod 51, 345-348.

6. Walker E, Pacold M, Perisic O, et al. (2000) Structural determinations of phosphoinositide 3-kinase inhibition by wortmannin, LY294002, quercetin, myricetin, and staurosporine. Mol Cell 6, 909-919.

7. Havsteen B (2002) The biochemistry and medical significance of the flavonoids. Pharmacol Ther 96, 67-202.

8. Dewick PM (2001) The shikimate pathway: aromatic amino acids and phenylpropanoids. In Medicinal Natural Products: a Biosynthetic Approach, 2nd ed., pp. 137-186 [PM Dewick, editor]. Chichester: John Wiley.

9. Griesbach R (2005) Biochemistry and genetics of flower color. Plant Breed Rev 25, 89-114.

10. Takahashi A \& Ohnishi T (2004) The significance of the study about the biological effects of solar ultraviolet radiation using the exposed facility on the international space station. Biol Sci Space 18, 255-260.

11. Samanta A, Das G \& Das S (2011) Roles of flavonoids in plants. Int J Pharm Sci Tech 6, 12-35.

12. Jorgensen R (1995) Co-suppression, flower color patterns, and metastable gene expression states. Science 268, 686-691.

13. Dixon R \& Pasinetti G (2010) Flavonoids and isoflavonoids: from plant biology to agriculture and neuroscience. Plant Physiol 154, 453-457.

14. Kumar S \& Pandey AK (2013) Chemistry and biological activities of flavonoids: an overview. ScientificW orldJournal 2013, 162750.

15. Panche A, Chandra S, Diwan A, et al. (2015) Alzheimer's and current therapeutics: a review. Asian J Pharm Clin Res 8, 14-19.

16. Manach C, Scalbert A, Morand C, et al. (2004) Polyphenols: food sources and bioavailability. Am J Clin Nutr 79, 727-747.

17. Iwashina $T$ (2013) Flavonoid properties of five families newly incorporated into the order Caryophyllales (Review). Bull Natl Mus Nat Sci 39, 25-51.

18. Matthies A, Clavel T, Gütschow M, et al. (2008) Conversion of daidzein and genistein by an anaerobic bacterium newly isolated from the mouse intestine. Appl Envrion Microbiol 74, 4847-4852. 
19. Aoki T, Akashi T \& Ayabe S (2000) Flavonoids of leguminous plants: structure, biological activity, and biosynthesis. J Plant Res 113, 475-488.

20. Dixon R \& Ferreira D (2002) Molecules of interest: genistein. Phytochemistry 60, 205-211.

21. Szkudelska K \& Nogowski L (2007) Genistein - a dietary compound inducing hormonal and metabolic changes. J Steroid Biochem Mol Biol 105, 37-45.

22. Linuma M, Tanaka T, Hamada K, et al. (1987) Revised structure of neoflavone in Coutarea hexandra. Phytochemistry 26, 3096-3097.

23. Nishimura S, Taki M, Takaishi S, et al. (2000) Structures of 4-arylcoumarin (neoflavone) dimers isolated from Pistacia chinensis BUNGE and their estrogen-like activity. Chem Pharm Bull (Tokyo) 48, 505-508.

24. Garazd M, Garazd Y \& Khilya V (2003) Neoflavones. 1. Natural distribution and spectral and biological properties. Chem Nat Comp 39, 54-121.

25. Giusti M \& Wrolstad R (2003) Acylated anthocyanins from edible sources and their applications in food systems. Biochem Eng J 14, 217-225.

26. Hertog MG, Hollman PC \& Van De PB (1993) Content of potentially anticarcinogenic flavonoids of tea infusions, wines, and fruit juices. J Agric Food Chem 41, 1242-1246.

27. Justesen U \& Knuthsen P (2001) Composition of flavonoids in fresh herbs and calculation of flavonoid intake by use of herbs in traditional Danish dishes. Food Chem 73, 245-250.

28. Stewart AJ, Bozonnet S, Mullen W, et al. (2000) Occurrence of flavonols in tomatoes and tomato-based products. I Agric Food Chem 48, 2663-2669.

29. Zheng W \& Wang SY (2001) Antioxidant activity and phenolic compounds in selected herbs. J Agric Food Chem 49, 5165-5170.

30. Atanassova M \& Bagdassarian V (2009) Rutin content in plant products. J Univ Chem Tech Met 44, 201-203.

31. Gudrais E (2012) Curbing clots. Harvard magazine. http://harvardmagazine.com (accessed June 2016).

32. Chang S, Tan C, Frankel E, et al. (2000) Low-density lipoprotein antioxidant activity of phenolic compounds and polyphenol oxidase activity in selected clingstone peach cultivars. J Agric Food Chem 48, 147-151.

33. Malagutti AR, Zuin V, Cavalheiro É, et al. (2006) Determination of rutin in green tea infusions using square-wave voltammetry with a rigid carbon-polyurethane composite electrode. Electroanalysis 18, 1028-1034.

34. Khan MT, Orhan I \& Enol SS (2009) Cholinesterase inhibitory activities of some flavonoid derivatives and chosen xanthone and their molecular docking studies. Chem Biol Interact 181, 383-389.

35. Thompson LU, Boucher BA, Liu Z, et al. (2006) Phytoestrogen content of foods consumed in Canada, including isoflavones, lignans, and coumestan. Nutr Cancer 54, 184-201.

36. Umpress ST, Murphy SP, Franke AA, et al. (2005) Isoflavone content of foods with soy additives. J Food Comp Anal 18, 533-550.

37. Krenn L, Unterrieder I \& Ruprechter R (2002) Quantification of isoflavones in red clover by high-performance liquid chromatography. J Chromatgr B 777, 123-128.

38. Coward L, Barnes NC, Setchell K, et al. (1993) Genistein, daidzein, and their $\beta$-glycoside conjugates: antitumor isoflavones in soybean foods from American and Asian diets. J Agric Food Chem 41, 1961-1967.

39. Kaufman PB, Duke JA, Brielmann H, et al. (1997) A comparative survey of leguminous plants as sources of the isoflavones, genistein and daidzein: implications for human nutrition and health. J Altern Complement Med 3, 7-12.

40. Gálvez MC, Barroso CG \& Pérez-Bustamante JA (1994) Analysis of polyphenolic compounds of different vinegar samples. $Z$ Lebensm Unters F A 199, 29-31.

41. Zhang Y, Wang GJ, Song TT, et al. (1999) Urinary disposition of the soybean isoflavones daidzein, genistein and glycitein differs among humans with moderate fecal isoflavone degradation activity. J Nutr 129, 957-962.
42. Cerezoa AB, Tesfayea W, Soria-Díazb ME, et al. (2010) Effect of wood on the phenolic profile and sensory properties of wine vinegars during ageing. J Food Comp Anal 23, 175-184.

43. Felgines C, Texier O, Morand C, et al. (2000) Bioavailability of the flavanone naringenin and its glycosides in rats. Am J Physiol Gastrointest Liver Physiol 279, G1148-G1154.

44. Rathmell WG \& Bendall DS (1971) Phenolic compounds in relation to phytoalexin biosynthesis in hypocotyls of Phaseolus vulgaris. Physiol Plant Pathol 1, 351-362.

45. Cruickshank IA, Biggs DR, Dawn PR, et al. (1974) Phaseollin and phaseollidin relationships in infection-droplets on endocarp of Phaseolus vulgaris. Physiol Plant Pathol 4, 261-276.

46. Hvattum E (2002) Determination of phenolic compounds in rose hip (Rosa canina) using liquid chromatography coupled to electrospray ionisation tandem mass spectrometry and diode-array detection. Rapid Commun Mass Spectrom 16, 655-662.

47. Sahu BD, Kalvala AK, Koneru M, et al. (2014) Ameliorative effect of fisetin on cisplatin-induced nephrotoxicity in rats via modulation of NF- $\mathrm{KB}$ activation and antioxidant defence. PLOS ONE 9, e105070.

48. Leung LK, Su Y, Chen R, Zhang Z, et al. (2001) Theaflavins in black tea and catechins in green tea are equally effective antioxidants. J Nutr 131, 2248-2251.

49. Truong V-D, Deighton N, Thompson RT, et al. (2010) Characterization of anthocyanins and anthocyanidins in purplefleshed sweetpotatoes by HPLC-DAD/ESI-MS/MS. J Agric Food Chem 58, 404-410.

50. Andreeva OA, Ivashev MN, Ozimina II, et al. (1998) Diosmetin glycosides from Caucasian vetch: isolation and study of biological activity. Pharm Chem I 32, 595-597.

51. Cai H, Al-Fayez M, Tunstall RG, et al. (2005) The rice bran constituent tricin potently inhibits cyclooxygenase enzymes and interferes with intestinal carcinogenesis in ApcMin mice. Mol Cancer Ther 4, 1287-1292.

52. Medjakovic S \& Jungbauer A (2008) Red clover isoflavones biochanin $\mathrm{A}$ and formononetin are potent ligands of the human aryl hydrocarbon receptor. J Steroid Biochem Mol Biol 108, 171-177.

53. National Agricultural Library (2014) Dr Duke's Phytochemical and Ethnobotanical Databases. Citrus aurantium L. https://phytochem.nal.usda.gov/phytochem/search/list (accessed June 2016).

54. Arts IC, Van De PB \& Hollman PC (2000) Catechin content of foods commonly consumed in the Netherlands. J Agric Food Chem 48, 1752-1757.

55. Ross JA \& Kasum CM (2002) Dietary flavonoids: bioavailability, metabolic effects, and safety. Annu Rev Nutr 22, 19-34.

56. Basli A, Soulet S, Chaher N, et al. (2012) Wine polyphenols: potential agents in neuroprotection. Oxid Med Cell Longev 2012, 805762.

57. Graver RJ \& Veitch NC (2006) Flavanones and dihydroflavonols. In Flavonoids: Chemistry, Biochemistry and Applications, pp. 918-1002 [OM Anderson and KR Markham, editors]. Boca Raton, FL: CRC Press/Taylor \& Francis Group.

58. Kawaii S, Tomono Y, Katase E, et al. (1999) Quantitation of flavonoid constituents in citrus fruits. J Agric Food Chem 47, 3565-3571.

59. Calderon-Montaño JM, Burgos-Moron E, Perez-Guerrero C, et al. (2011) A review on the dietary flavonoid kaempferol. Mini Rev Med Chem 11, 298-344.

60. Liu RH (2013) Health-promoting components of fruits and vegetables in the diet. Adv Nutr 4, 384S-392S.

61. Kim SH \& Choi KC (2013) Anti-cancer effect and underlying mechanism(s) of kaempferol, a phytoestrogen, on the regulation of apoptosis in diverse cancer cell models. Toxicol Res 29, 229-234.

62. Kayoko S, Hisae O, Michiyo F, et al. (1998) Intestinal absorption of luteolin and luteolin 7-O- $\beta$-glucoside in rats and humans. FEBS Lett 438, 220-224.

63. López-Lázaro M (2009) Distribution and biological activities of the flavonoid luteolin. Mini Rev Med Chem 9, 31-59.

64. Perry EK, Tomlinson BE, Blessed G, et al. (1978) Correlation of cholinergic abnormalities with senile plaques and mental test scores in senile dementia. Br Med J 2, 1457-1459. 
65. Sheng R, Lin X, Zhang J, et al. (2009) Design, synthesis and evaluation of flavonoid derivatives as potent AChE inhibitors. Bioorg Med Chem 17, 6692-6698.

66. Smith R, DeWitt D \& Garavito R (2000) Cyclooxygenases: structural, cellular and molecular biology. Ann Rev Biochem 69, 145-182.

67. Kurumbail R, Stevens A, Gierse J, et al. (1996) Structural basis for selective inhibition of cyclooxygenase 2 by anti-inflammatory agents. Nature 384, 644-648.

68. Kujubu D, Fletcher B, Varnum B, et al. (1991) TIS10, a phorbol ester tumor promoter-inducible mRNA from Swiss 3T3 cells, encodes a novel prostaglandin synthase/cyclooxygenase homologue. I Biol Chem 266, 12866-12872.

69. D’Mello P, Gadhwal M, Joshi U, et al. (2011) Modeling of COX-2 inhibitory activity of flavonoids. Int J Pharm Pharm Sci 3, 33-40.

70. Madeswaran A, Umamaheswari M, Asokkumar K, et al. (2012) In-silico docking studies of cyclooxygenase inhibitory activity of commercially available flavonoids. Asian J Pharm Life Sci 2, 174-181.

71. Madeswaran A, Umamaheswari M, Asokkumar K, et al. (2011) In-silico docking studies of lipoxygenase inhibitory activity of commercially available flavonoids. J Comput Method Mol Des 1, 65-72.

72. Wu C, Wu S, Chung W, et al. (2007) Antiplatelet effect and selective binding to cyclooxygenase (COX) by molecular docking analysis of flavonoids and lignans. Int J Mol Sci 8, 830-841.

73. Hatti K, Diwakar L, Rao G, et al. (2009) Abyssinones and related flavonoids as potential steroidogenesis modulators. Bioinformation 3, 399-402.

74. Borges F, Fernandes E \& Roleira F (2002) Progress towards the discovery of xanthine oxidase inhibitors. Curr Med Chem $\mathbf{9}$, 195-217.

75. Hille R (1996) The mononuclear molybdenum enzymes. Chem Rev 96, 2757-2816.

76. Alnajiar B (2008) Computational studies of natural flavonoids towards the discovery of a potential xanthine oxidase inhibitor. MSc Thesis, Universiti Sains, Malaysia.

77. Umamaheswari M, Madeswaran A, Kuppusamy A, et al. (2011) Discovery of potential xanthine oxidase inhibitors using in silico docking studies. Der Pharma Chemica 3, 240-247.

78. Shoba G, Hari S, Prabhavathi G, et al. (2010) Flavonoids - natural therapeutic agents for polycystic kidney disease. Int J Pharm Bio Sci 1, B89-B105.

79. Lin W, Xie J, Wu X, et al. (2014) Inhibition of xanthine oxidase activity by gnaphalium affine extract. Chin Med Sci J 29, 225-230.

80. De Souza V, De Franco E, De Araujo M, et al. (2016) Characterization of the antioxidant activity of aglycone and glycosylated derivatives of hesperetin: an in-vitro and in-vitro study. J Mol Recognit 29, 80-87.

81. Lee J, Jeong K, Shin S, et al. (2011) Antimicrobial natural products as $\beta$-ketoacyl-acyl carrier protein synthase III inhibitors. Bioorg Med Chem 17, 5408-5413.

82. Ganugapati J, Sirisha V, Mukkavalli S, et al. (2011) Insilico modeling and docking studies of New Delhi metallo $\beta$ lactamase-1 (super bug). Int J Eng Sci Tech 3, 2427-2434.

83. Padmavathi M, Prasanth Reddy V \& Rao R (2012) Inhibition of NDM-1 in superbugs by flavonoids - an insilico approach. $J A d v$ Bioinfo App Res 3, 328-332.

84. Ganugapati J, Mukkavalli S \& Sahithi A (2011) Docking studies of green tea flavonoids as insulin mimetics. Int J Comp App 30, 48-52.

85. Lu S \& Chong F (2012) Combining molecular docking and molecular dynamics to predict the binding modes of flavonoid derivatives with the neuraminidase of the 2009 H1N1 influenza A virus. Int J Mol Sci 13, 4496-4507.

86. Cardenas H, Arango D, Nicholas C, et al. (2016) Dietary apigenin exerts immune-regulatory activity in vivo by reducing NF- $\mathrm{KB}$ activity, halting leukocyte infiltration and restoring normal metabolic function. Int J Mol Sci 17, 323.

87. Kim K, Vance TM \& Chun OK (2016) Greater flavonoid intake is associated with improved CVD risk factors in US adults. BrJ Nutr $115,1481-1488$.
88. Mulvihill E, Burke A \& Huff M (2016) Citrus flavonoids as regulators of lipoprotein metabolism and atherosclerosis. Annu Rev Nutr 36, 275-299.

89. Hügel HM, Jackson N, May B, et al. (2016) Polyphenol protection and treatment of hypertension. Phytomedicine 23, 220-231.

90. Brüll V, Burak C, Stoffel-Wagner B, et al. (2015) Effects of a quercetin-rich onion skin extract on $24 \mathrm{~h}$ ambulatory blood pressure and endothelial function in overweight-to-obese patients with (pre-) hypertension: a randomised double-blinded placebocontrolled cross-over trial. Br J Nutr 114, 1263-1277.

91. Schiavano GF, De Santi M, Brandi G, et al. (2015) Inhibition of breast cancer cell proliferation and in vitro tumorigenesis by a new red apple cultivar. PLOS ONE 10, e0135840.

92. Wallace TC, Slavin M \& Frankenfel CL (2016) Systematic review of anthocyanins and markers of cardiovascular disease. Nutrients 8,32 .

93. Pribac G, Sferdian M, Neamțu C, et al. (2015) Fenugreek powder exerts protective effects on alcoholised rat's kidney, highlighted using ultrastructural studies. Rom J Morphol Embryol 56, 445-451.

94. da Silva SM, Koehnlein EA, Bracht A, et al. (2014) Inhibition of salivary and pancreatic $\alpha$-amylases by a pinhão coat (Araucaria angustifolia) extract rich in condensed tannin. Food Res Int 56, 1-8.

95. Oliveira R, Gonçalves G, Inácio F, et al. (2015) Inhibition of pancreatic lipase and triacylglycerol intestinal absorption by a pinhão coat (Araucaria angustifolia) extract rich in condensed tannin. Nutrients 7, 5601-5614.

96. Hayden E, Yamin G, Beroukhim S, et al. (2015) Inhibiting amyloid $\beta$-protein assembly: size-activity relationships among grape seedderived polyphenols. J Neurochem 135, 416-430.

97. Paris D, Mathura V, Ghezala G, et al. (2011) Flavonoids lower Alzheimer's $A \beta$ production via an NFאB dependent mechanism. Bioinformation 6, 229-236.

98. Alzheimer's Disease International (2011) World Alsheimer Report 2010. The Global Economic Impact of Dementia. London: Alzheimer's Disease International.

99. Terry R, Masliah E, Salmon D, et al. (1991) Physical basis of cognitive alterations in Alzheimer's disease: synapse loss in the major correlate of cognitive impairment. Ann Neurol 30, 572-580.

100. Shimmyo Y, Kihara T, Akaike A, et al. (2008) Flavonols and flavones as BACE-1 inhibitors: structure-activity relationship in cellfree, cell-based and in-silico studies reveal novel pharmacophore features. Biochem Biophy Acta 1780, 819-825.

101. Swaminathan M, Chin F, Sek P, et al. (2014) Flavonoids with M1 muscarinic acetylcholine receptor binding activity. Molecules 19, 8933-8948.

102. Fisher A (2008) Cholinergic treatments with emphasis on M1 muscarinic agonists as potential disease-modifying agents for Alzheimer's disease. Neurotherapeutics 5, 433-442.

103. DeGroot H (1994) Reactive oxygen species in tissue injury. Hepatogastroenterology 41, 328-332.

104. Grace PA (1994) Ischaemia-reperfusion injury. Br J Surg 81, 637-647.

105. Halliwell B (1995) How to characterize an antioxidant: an update. Biochem Soc Symp 61, 73-101.

106. Nijveldt R, Nood E, Hoorn D, et al. (2001) Flavonoids: a review of probable mechanisms of action and potential applications. $A m \mathrm{~J}$ Clin Nutr 74, 418-425.

107. Codorniu-Hernández E, Rolo-Naranjoa A \& Montero-Cabrera LA (2007) Theoretical affinity order among flavonoids and amino acid residues: an approach to understand flavonoid-protein interactions. J Mol Struc: THEOCHEM 819, 121-129.

108. Korkina L \& Afanasev I (1997) Antioxidant and chelating properties of flavonoids. Adv Pharmacol 38, 151-163.

109. Hanasaki Y, Ogawa S \& Fukui S (1994) The correlation between active oxygens scavenging and antioxidative effects of flavonoids. Free Radic Biol Med 16, 845-850.

110. Kerry N \& Abbey M (1997) Red wine and fractionated phenolic compounds prepared from red wine inhibit low density lipoprotein oxidation in vitro. Atherosclerosis 135, 93-102. 
111. Sanhueza J, Valdes J, Campos R, et al. (1992) Changes in the xanthine dehydrogenase/xanthine oxidase ratio in the rat kidney subjected to ischemia-reperfusion stress: preventive effect of some flavonoids. Res Commun Chem Pathol Pharmacol 78, 211-218.

112. Shoskes D (1998) Effect of bioflavonoids quercetin and curcumin on ischemic renal injury: a new class of renoprotective agents. Transplantation 66, 147-152.

113. Chang W, Lee Y, Lu F, et al. (1993) Inhibitory effects of flavonoids on xanthine oxidase. Anticancer Res 13, 2165-2170.

114. Cos P, Ying L, Calomme M, et al. (1998) Structure-activity relationship and classification of flavonoids as inhibitors of xanthine oxidase and superoxide scavengers. I Nat Prod 61, 71-76.

115. Friesenecker B, Tsai A, Allegra C, et al. (1994) Oral administration of purified micronized flavonoid fraction suppresses leukocyte adhesion in ischemia-reperfusion injury: in-vitro observations in the hamster skin fold. Int J Microcirc Clin Exp 14, 50-55.

116. Friesenecker B, Tsai A \& Intaglietta M (1995) Cellular basis of inflammation, edema and the activity of Daflon $500 \mathrm{mg}$. Int J Microcirc Clin Exp 15, 17-21.

117. Ferrandiz M, Gil B \& Sanz M (1996) Effect of bakuchiol on leukocyte functions and some inflammatory responses in mice. J Pharm Pharmacol 48, 975-980.

118. Alcaraz M \& Ferrandiz M (1987) Modification of arachidonic metabolism by flavonoids. J Ethnopharmacol 21, 209-229.

119. Jager A \& Saaby L (2011) Flavonoids and the CNS. Molecules 16, 1471-1485.

120. Hu Y, Yanhong S, Jing Z, et al. (2009) Synthesis and biological evaluation of novel flavonoid derivatives as dual binding acetylcholinesterase inhibitors. J Ensyme Inbib Med Chem 24, 372-380.

121. Croteau R, Kutchan TM \& Lewis NG (2000) Natural products (secondary metabolites). In Biochemistry and Molecular Biology of Plants, pp. 1250-1318 [B Buchanan, W Gruissem and R Jones, editors]. Rockville, MD: American Society of Plant Biologists.

122. Wink M (2004) Phytochemical diversity of secondary metabolites. In Encyclopedia of Plant and Crop Science, pp. 915-919. New York: Marcel Dekker, Inc.

123. Anand S (2010) Various approaches for secondary metabolite production through plant tissue culture. Pharmacia 1, 1-7.

124. Hussain MS, Fareed S, Ansari S, et al. (2012) Current approaches toward production of secondary plant metabolites. J Pharm Bioallied S Si 4, 10-20.

125. Srivastava N \& Bezwada R (2015) Flavonoids: The Health Boosters. White Paper. Hillsborough, NJ: Indofine Chemical Company.

126. Hossain H, Shahid-Ud-Daula A, Jahan I, et al. (2012) Evaluation of antinociceptive and antioxidant potential from the leaves of Spilanthes paniculata growing in Bangladesh. Int J Pharm Phytopharmacol Res 1, 178-186.

127. Snijman P, Swanevelder S, Joubert S, et al. (2007) The antimutagenic activity of the major flavonoids of rooibos (Aspalatbus linearis): some dose-response effects on mutagen activationflavonoid interactions. Mutat Res 631, 111-123.

128. LeJeune TM, Tsui HY, Parsons LB, et al. (2015) Mechanism of action of two flavone isomers targeting cancer cells with varying cell differentiation status. PLOS ONE 10, e0142928.

129. Kim H, Son K, Chang H, et al. (2004) Anti-inflammatory plant flavonoids and cellular action mechanisms. J Pharmacol Sci 96, 229-245.

130. Ren W, Qiao Z, Wang H, et al. (2003) Flavonoids: promising anticancer agents. Med Res Rev 23, 519-534.

131. Kitagawa S, Fujisawa H \& Sakurai H (1992) Scavenging effects of dihydric and polyhydric phenols on superoxide anion radicals, studied by electron spin resonance spectrometry. Chem Pharm Bull 40, 304-307.

132. Lale A, Herbert J, Augereau J, et al. (1996) Ability of different flavonoids to inhibit the procoagulant activity of adherent human monocytes. J Nat Prod 59, 273-276.

133. Hertog M, Sweetnam P, Fehily A, et al. (1997) Antioxidant flavonols and ischemic heart disease in a Welsh population of men: the Caerphilly Study. Am J Clin Nutr 65, 1489-1494.
134. Haraguchi H, Saito T, Ishikawa H, et al. (1996) Antiperoxidative components in Thymus vulgaris. Planta Med 62, 217-221.

135. Ishikawa T, Suzukawa M, Ito T, et al. (1997) Effect of tea flavonoid supplementation on the susceptibility of low-density lipoprotein to oxidative modification. Am J Clin Nutr 66, 261-266.

136. Katan MB \& Hollman PCH (1998) Dietary flavonoids and cardiovascular disease. Nutr Metab Cardiovasc Dis 8, 1-4.

137. Pietta PG (2000) Flavonoids as antioxidants. J Nat Prod 63, 1035-1042.

138. Halliwell B (1991) Drug antioxidant effects. A basis for drug selection? Drugs 42, 569-605.

139. Halliwell B (1991) Reactive oxygen species in living systems: source, biochemistry, and role in human disease. Am J Med 91, 14S-22S.

140. Halliwell B, Gutteridge J \& Cross C (1992) Free radicals, antioxidants, and human disease: where are we now? J Lab Clin Med 119, 598-620.

141. Letan A (1966) The relation of structure to antioxidant activity of quercetin and some of its derivatives. J Food Sci 31, 395-399.

142. Wang H, Xia Y, Yang Z, et al. (1998) Recent advances in the discovery and development of flavonoids and their analogues as antitumor and anti-HIV agents. Adv Exp Med Biol 439, 191-225.

143. Kaul T, Middleton E \& Ogra P (1985) Antiviral effect of flavonoids on human viruses. J Med Virol 15, 71-79.

144. Wu D, Kong Y, Han C, et al. (2008) D-Alanine: D-alanine ligase as a new target for the flavonoids quercetin and apigenin. Int $J$ Antimicrob Agents 32, 421-426.

145. Li M \& Xu Z (2008) Quercetin in a lotus leaves extract may be responsible for antibacterial activity. Arch Pharm Res 31, 640-644.

146. Wiseman H (2000) The therapeutic potential of phytoestrogens. Exp Opin Investig Drugs 9, 1829-1840.

147. Metzner J, Frank T, Kunz I, et al. (2009) Study on the pharmacokinetics of synthetic genistein after multiple oral intake in postmenopausal women. Arzneimittelforscbung 59, 513-520.

148. Tikkanen MJ \& Adlercreutz H (2000) Dietary soy-derived isoflavone phytoestrogens. Could they have a role in coronary heart disease prevention? Biochem Pharmacol 60, 1-5.

149. Tham D, Gardner C \& Haskell W (1998) Clinical review 97: potential health benefits of dietary phytoestrogens: a review of the clinical, epidemiological and mechanistic evidence. J Clin Endocrinol Metab 83, 2223-2235.

150. Comalada M, Camuesco D, Sierra S, et al. (2005) In vivo quercitrin anti-inflammatory effect involves release of quercetin, which inhibits inflammation through down-regulation of the NF- $\mathrm{KB}$ pathway. Eur J Immunol 35, 584-592.

151. Fotsis T, Pepper M, Aktas E, et al. (1997) Flavonoids, dietaryderived inhibitors of cell proliferation and in vitro angiogenesis. Cancer Res 57, 2916-2921.

152. Si H \& Liu D (2007) Phytochemical genistein in the regulation of vascular function: new insights phytochemical genistein in the regulation of vascular function: new insights. Curr Med Chem 14, 2581-2589.

153. Kamaraj S, Ramakrishnan G, Anandakumar P, et al. (2009) Antioxidant and anticancer efficacy of hesperidin in benzo (a)pyrene induced lung carcinogenesis in mice. Invest New Drugs 27, 214-222.

154. Arafa S, Zhu Q, Barakat B, et al. (2009) Tangeretin sensitizes cisplatin-resistant human ovarian cancer cells through down regulation of phosphoinositide 3-kinase/Akt signaling pathway. Cancer Res 69, 8910-8917.

155. Huang JH, Huang CC, Fang JY, et al. (2010) Protective effects of myricetin against ultraviolet-B-induced damage in human keratinocytes. Toxicol In Vitro 24, 21-28.

156. Beking K \& Vieira A (2010) Flavonoid intake and disability-adjusted life years due to Alzheimer's and related dementias: a population-based study involving twenty-three developed countries. Public Health Nutr 13, 1403-1409.

157. Hwang S \& Yen G (2008) Neuroprotective effects of the citrus flavanones against $\mathrm{H}_{2} \mathrm{O}_{2}$-induced cytotoxicity in PC12 cells. J Agric Food Chem 56, 859-864.

158. Waisundara V, Hsu A, Tan B, et al. (2009) Baicalin reduces mitochondrial damage in streptozotocin-induced diabetic Wistar rats. Diabetes Metab Res Rev 25, 671-677. 
159. Zhang L, Jie G, Zhang J, et al. (2009) Significant longevity-extending effects of EGCG on Caenorbabditis elegans under stress. Free Radic Biol Med 46, 414-421.

160. Meng Q, Velalar C \& Ruan R (2008) Effects of epigallocatechin-3gallate on mitochondrial integrity and antioxidative enzyme activity in the aging process of human fibroblast. Free Radic Biol Med 44, 1032-1041.

161. Saul N, Pietsch K, Menzel R, et al. (2009) Catechin induced longevity in $C$. elegans: from key regulator genes to disposable soma. Mech Ageing Dev 130, 477-486. 